\title{
"I had no idea until I got into It but I would not Change it for Anything. I love what I do": General Education Teachers as Special Educators in Rural Schools
}

\author{
Susan P. Gregory \\ Montana State University Billings \\ United States of America
}

\begin{abstract}
For several years, the United States has faced a shortage of special education teachers with the need particularly acute in more rural parts of the county. As a result, some states have developed alternative certification programs to assist schools in filling these positions. Montana is one such state where licensed general education teachers can teach in a special education classroom for up to three years while the teacher obtains their special education credentials. In this study, phone interviews were conducted with eighteen Montana teachers who had taken these positions. The purpose of the interviews was to find out their experiences in those first years of teaching in a special education classroom in a rural school. Many of these teachers were the only special education teacher in their school. Some had previous teaching experience in the general education classroom and others did not. Each of these teachers was also enrolled at a university, taking coursework to obtain a special education credential while they also learned the responsibilities of their position in their respective schools. This study examined the benefits and the challenges that these teachers experienced.
\end{abstract}

\section{Introduction}

In the United States, a critical shortage of special education teachers has existed for several years [1], [2]. The National Coalition on Personnel Shortages in Special Education and Related Services consists of over thirty national organizations, which collect data on these shortages and advocates for solutions at the state and national level. They report that special education teachers leave the profession at double the rate of general education teachers and that forty-nine states report a shortage of special education teachers.

This shortage is more acute in rural areas [3]. Berry and her colleagues [1] conducted a national sample of rural special education administrators and teachers and their study highlighted the difficulties in attracting and recruiting teachers to rural areas and that "the demands of the position in rural areas place teachers at a greater risk for attrition" (p.10). Distance from other teachers in similar positions, and from professional development opportunities at universities, are contributing factors.

To meet the lack of qualified special education teachers, many states have developed alternative routes to special education certification [4], [5], [2]. These alternative programs allow unlicensed individuals to become licensed teachers while working in schools. Typically, the teachers are responsible for a classroom while they are also taking university coursework. The need for these teachers is most evident in rural communities. This has led to the development of programs which prepare teachers in the field of special education, thereby meeting the needs of these rural schools. In one example, Childe [5] describes a program which was developed in partnership with a university and was designed to meet the needs of rural Georgia where there was shortage of special education teachers. This program was typical of those that train teachers in rural areas. The teachers in these areas are often far from a university campus making it more difficult for them to attend classes. Online instruction for these teachers becomes a necessity, as Erickson and her colleagues have noted [6].

Montana is a large rural state, known for its Western culture and stunning landscapes. It is known as Big Sky country because of the large expanse of open sky across the rural landscapes and is home to seven American Indian reservations. According to the census data, Montana ranks 4 th in size and $44^{\text {th }}$ in population with the estimated population being 6.8 people per square mile [7]. There is only one city in the state with a population of over 100,000. The rural nature of the state presents challenges. Mountainous areas of the state and long distances between towns can make travel difficult, particularly during the winter months when snow storms make travel hazardous and cell phone service in parts of the state is intermittent. These factors have contributed to the growth of online learning in the state as teachers have faced difficulties in traveling to universities to take courses. 
The need for special education teachers in Montana has been consistent over the years [8], [9]. Rural schools in Montana have found it particularly challenging to attract teachers to fill special education positions. In addition, specialization within the field is not viable. The rural nature of the state means that school districts cannot expect to have more than one special education teacher each specializing in serving only children with a specific disability, such as learning disabilities or autism. The special education teacher in a rural Montana school has to be able to serve children with all types of special needs and all school ages. University preparation programs in Montana have to prepare special education teachers to be able to teach children with special needs from preschool age until $12^{\text {th }}$ grade, that is from age 3-18. As the law requires that those children be served by school districts it also means that the teacher in a smaller more rural school may be serving children with a range of disabilities and a range of grade levels from elementary to high school age. Because of its history and the rural nature of the state, one-room schoolhouses were prevalent. These are schools with one room in which children from Kindergarten to $12^{\text {th }}$ grade are served. Although the numbers of these schools has significantly declined, Montana still has the largest number of one-room schoolhouses in the nation.

Another challenge facing districts is that Montana has one of the lowest starting teacher salaries in the nation, making it difficult to attract qualified teachers. When there is a nationwide shortage of special education teachers, qualified special education teachers have a range of options of where to teach.

The Office of Public Instruction (OPI) is Montana's department of education. In the latest information reported by their office, they identified special education as one of the critical education shortage areas for the 2015-16 school year. They reported that across the state there were 191 vacant positions in special education with at least $80 \%$ of those positions being difficult or very hard to fill [10].

The state of Montana requires teachers of students with special needs to have a teaching license and to have a special education endorsement on their teaching license. The special education endorsement is obtained through a program of study at an accredited higher education institution. In Montana, several institutions which provide these programs. The state expects that this program of study will prepare teachers to be able to teach students with special needs from preschool to $12^{\text {th }}$ grade or until they graduate from school. These programs of study must also prepare teachers to be able to teach students with all types of disabilities, for example, learning disabilities, intellectual disabilities, autism, and behavior disorders. As the state is rural it is unrealistic to expect schools to be able teachers to specialize in teaching students with specific disabilities, as so many schools have difficulty in hiring one teacher.
Therefore, a generalist special education teacher model has evolved in Montana. This means that schools can expect recruit special education teachers who are prepared to meet the needs of children with a variety of special education needs and ages.

Recognizing the difficulties that rural schools were having in attracting qualified special education teachers, Montana's Office of Public Instruction (OPI) started a project known as the Special Education Endorsement Project. A school district that is unable to attract a teacher qualified to teach students with special needs could submit an application to the project. If the application meets the project criteria, then that teacher is eligible to receive a stipend from OPI towards the cost of their university expenses. OPI requires these licensed teachers complete their endorsement within a three-year limit. The project also provides mentorship for the teachers in their first year. Teachers are paired with a mentor who is a licensed teacher and typically that mentor provides the support online. Teachers in the project are teaching and being mentored in their first year and are given three years to complete their special education endorsement from one of the state universities.

\section{Description of the study}

The purpose of this study was to examine the experience of those licensed Montana teachers as they navigated those first three years teaching students in rural schools. These teachers were from schools across the whole state of Montana. The teachers were in their first, second or third years teaching in a special education position while taking courses leading to the state's required endorsement in special education.

\subsection{Procedure}

During the 2014-2017 period, there were thirty teachers who started with the OPI Special Education Endorsement Project. All were licensed teachers but none had an endorsement to teach students with special needs when they started in the project. The majority of the teachers had taught in the general education classroom for several years. A letter was sent to each of these teachers in OPI Special Education Endorsement Project with an overview of the study, an invitation to participate and a consent form to be returned in an addressed envelope. A follow up invitation was sent one month later and eighteen of the thirty teachers agreed to participate representing a $60 \%$ response rate.

The teachers who returned consent forms were contacted and arrangements were made for a convenient time to interview them individually by phone. In most cases, the phone interviews took place in the summer of 2017, after the school year had finished and were conducted by the author. Each teacher was asked for his or her consent to record the interview so that the interview could be later 
transcribed. Assurances were given that no identifying information, including the names of schools, teachers or students, would be shared. Each individual interview took approximately 30-40 minutes.

The teachers were all in rural schools of different sizes. They were in elementary, middle and high school positions and each had different caseloads of students. Of the eighteen teachers interviewed, fifteen were female and three were male. Half of the teachers had less than four years prior teaching experience as a general education teacher and five of that group had no previous teaching experience at all. The other nine teachers interviewed had between five and twenty years teaching experience in a general education setting. The focus of the interviews was to examine what these teachers had found to be beneficial and what they had found challenging in their first year taking on their role as the special education teacher. They were asked open-ended questions in that they were asked to describe the benefits and challenges they faced in teaching special education as they learned their new role. Each phone interview lasted for approximately 30-40 minutes. The author from the recordings of the phone interviews transcribed the interviews. All identifying information was removed and codes were assigned to each transcript. Then the author and the project coordinator of the OPI Special Education Endorsement Project each analyzed the transcripts independently. They analyzed teacher responses, and identified themes from the transcripts. Then they collectively reviewed the themes they had identified and those areas of agreement.

\section{Results}

The teachers were asked why they had applied for the special education position. There were two main reasons that these general education teachers applied for the special education position. The first reason was location. Some of the teachers had been looking for a teaching position in Montana generally or in a specific area of the state in order to be closer to their family. Other teachers had applied for a position because their partner had taken a job in the area and so they were looking for a teaching position in that area.

"I love Montana rural schools. I love farming communities".

"I was very interested in teaching in a certain area in Montana and they needed someone who was willing to teach special education".

The second reason teachers applied for the position were those teachers who were already teaching in that district in the general education classroom and who were aware of the vacant position. They saw the difficulty that the district was having in recruiting a special education teacher to fill that position. Some teachers were asked by their administration to apply and other teachers had decided to apply when they saw the need in their school.
"I know that they didn't even have anyone apply for the position when they ran it before they asked me".

"We're a very small school and there was a lack of special education teachers and we were looking at the possibility that we wouldn't be able to replace the special education teacher that was leaving. So I told my administration that I would be willing to get my endorsement because I didn't want to see those kids not receive services".

\subsection{Benefits of teaching special education in the rural school}

When asked about the nature of teaching in a rural school the teachers were generally positive about the rural school experience. Many talked about the closeness of the staff and the students as this teacher expressed.

"I love rural schools. I think your staff is tighter knit and you know your students better".

A smaller school has the potential to bring staff and students closer together. In their responses, the teachers clearly felt that this afforded them the opportunity to have a better understanding of their students. Special education teachers are responsible for overseeing the student's Individualized Education Plan and monitoring progress on the student's goals. Each special education teacher has a caseload of students that they are responsible for and not all of these students will be in the teacher's classroom for the whole day. For example in a resource room, the students will come for only part of the day and then return to the general education classroom. In a smaller school, there are fewer students and consequently a smaller number of students with special needs. The teachers that were interviewed stated that teaching in a rural school meant that their caseloads were smaller than in larger districts and for some this was a real benefit. This not only gave them the opportunity to work individually with students but they said this afforded them a closer connection to those students. They appreciated that connection as this teacher noted:

"I like teaching in small schools there's more intimacy with the kids, you get to know them better".

The teachers described the connections they developed with families and the culture of being in a rural community facilitated those connections. The smaller school meant that they could follow the development of individual students more closely.

"I like rural settings just because you get to know the kids and the families and to me that's the most important. You get to build those relationships. You see them grow. I like small schools for that simple reason".

"I like the sense of community. We know most of the parents. We know all the kids. We are able to spend more time with the kids".

The sense that families felt more connected to the school extended to grandparents as in this teacher's 
opinion as the teacher described the setting as potentially less intimidating.

"I think people feel more comfortable coming in to a smaller school if they are invited. When I was in a larger school I could never get grandparents to come in even though I begged them".

The teachers described the overall sense of community that comes from teaching in a rural school and this extended to after school activities. Teachers are not only expected to participate in after school activities, such as monitoring dances and athletic events but many do so because they like to support their students and see families in a more informal context. In rural communities, the school is often a focus of the local community particularly where athletic events are the focus. Teams and events are supported by the community not just the friends and family of the students. Because many of these smaller schools are located in farming communities one teacher in the interviews even mentioned an invitation to participating on a family's cattle drive. When cattle need to be moved from one location to another it is typically done on horseback, hence the name, cattle drive and this is a familiar sight in Western states.

\subsection{Challenges of teaching special education in the rural school}

Integral to the special education process in the United States is the Individualized Education Plan (IEP). A team develops the IEP and the special education teacher plays a key role in the development of the goals on that plan. The special education teacher is also the primary person responsible for monitoring student progress on the goals and for communicating with the general education teacher on student accommodations that are needed. Ultimately, the IEP is a legal document, which if not implemented correctly, can potentially lead to litigation. This results in a certain apprehension for novice special education teachers learning the language and the process of IEP development and implementation. The teachers in this study were no exception.

"The hardest thing for me was the language for the IEPs".

"One thing I did learn was document document document. That was something I didn't realize was involved with the job. I love the teaching side of the job but the paperwork sometimes gets daunting".

The second main challenge that many of these teachers mentioned was the lack of resources. "I've had zero money zero budget. I've spent a ton of my own money on things, which is typical of teachers". Another teacher reported, "We don't have a lot of equipment and it has to be shared".

Schools in Montana receive funding through a combination of state and local funding and the amount of state support has declined in recent years, with a greater share falling on local communities. For many of the smaller schools this inevitably means that there may not be funding for materials. Teachers in general are known for purchasing many materials with their own money.

The third main challenge for these teachers is supporting the needs of the students with related services. Special education law specifies that students with special educational needs can have services that are related to their needs. Known as related services, these can include services such as physical therapy, speech therapy and occupational therapy. Not every student will need these related services but if they do, they must be written into the student's IEP with the number of occasions they will be delivered and who is responsible for them. Larger school districts will have their own related service professionals who will visit students in those schools on a regular schedule. Rural schools will share related services usually through a special education cooperative. However, the reality of related service providers bringing their services to students with special needs in rural schools is a challenge as these teachers reported.

"Lack of services. We just don't have as many available and a lot of times they have to travel for those services. Take speech for example. We don't have a speech therapist and when we need one face to face she has to travel two and a half hours just to get here."

One teacher mentioned that the occupational therapist for their school is from another state and works with the students remotely. Another teacher said they had speech therapists from three different states working with students in her class through remote supervision. This meant that the related service provider was not physically present in the school and that a staff member needed to sit with the student and take direction from the speech therapist while she worked with the student remotely.

The fourth main challenge for the teachers was the transition into a new role. Many of these teachers already had many years teaching in general education and in this new role, they were often the only specialist in that area in the school. This was a new experience and reflected in their comments. Some teachers spoke of the feeling of isolation and lack of another colleague in the same building with whom they could share ideas.

"I felt like I was out on an isle. There was no other sped teacher that I could go to...It would be nice to have someone that could come on site just to brainstorm with".

"I went from being on a team to being on my own...sometimes I consider it a lonely place, my own little island. That's something I had not anticipated happening".

"There was no other special education teacher I could go to...It would have been nice to have someone that could come on site just to brainstorm with."

The move from being part of the general education community of teachers to being a specialist brought a feeling of separateness that they had not anticipated. 
The special education teacher typically is in their own classroom working with either students in that room for all or part of the day. Jones and his colleagues [11] also noted this in their research. They used the example of subject areas teachers, such as math teachers. Those teachers can identify with colleagues teaching the same subject area. However, in special education that teacher usually will not have other colleagues in the school that are readily accessible.

In addition to this challenge, some of the teachers alluded to the fact that in moving to this new role, they were responsible for collaborating with the convincing those teachers of the value of their role, the needs of their students and the importance of working together. This was a new experience for some of the teachers.

"My biggest challenge with the other teachers is that they don't see the importance of my job."

"I think the thing I am struggling with the most is how I convey the needs of my students to the regular education teachers".

"Making classroom teachers understand that it's not my sole responsibility to teach students with special needs, it's our responsibility".

These teachers were experiencing that challenge of being in a specialist role and collaborating with the general education teacher.

\subsection{Future}

In concluding the interviews with the teachers, some made unsolicited comments about discovering that they had an affinity for the special education role. Despite the fact that they had not fully understood the scope of the job that enjoyed working as a special education teacher and even suggested that they were not planning to return to teaching general education. "I had no idea until I got into it but I would not change it for anything. I love what I do".

"I enjoy my job it's rewarding."

"I was hesitant at first when I started but I really have had a good experience."

"I feel blessed to be in this program. I think special ed is a good fit for me."

"I have never had a position in what I went to college for and now if that position were to open up I don't think I would go. My heart is into this."

"The first year was really tough. It was harder than I thought it would be. There's definitely more to it than I thought there would be."

\section{Discussion}

From these interviews, it is evident that the culture of rural communities benefits the schools in those communities. There are those general education teachers that have a close connection to their school and their students and see a need which they decide to fill when the school is unable to find a special education teacher for that position. This seems to speak to that sense of community fostered in the smaller school.

This sense of community extends to the relationship with their students and the students' families. The majority of these special education teachers had smaller caseloads compared to teachers in more urban schools. This gave them more opportunity for individualized instruction and a feeling that they knew their students better than if they worked in a larger school.

One of the main challenges that those teachers faced were the Individualized Education Plan (IEP) process and the associated paperwork. In Montana, teachers are required to enter the IEP information into a specific electronic format. Therefore, Montana teachers have to learn the components of the IEP, the format of developing student goals on that plan and learn the electronic format required by the state. Developing IEP's, and the volume of paperwork that special education teachers need to complete on each student, has been recognized as one reason teachers have left the profession. Jones and his colleagues [11] reported in a study by Vannest and Hagan-Burke [12] that at least $12 \%$ of a special education teacher's time is spent on paperwork. One solution is to ensure that these teachers have the needed support in their first year of teaching in special education. The OPI Special Education Endorsement Project provides a mentor to each teacher in his or her first year of the project. However as many of the mentors are not within traveling distance, they provide support online. The state also provides workshops to new teachers on developing IEPs but it was clear from the interviews that not all the teachers had been able to attend these workshops and even those that had felt that they needed more assistance when it came to writing an IEP on their own. As the paperwork and IEP development are significant challenges for these teachers it is important that supports are given to them early in developing skills in this area. A one-time workshop may not be sufficient to teachers mastering these skills.

It is understandable that restricted budgets in a smaller school and lack of more readily available resources would be a challenge for these special education teachers. Students with special needs often require additional and more specialized materials and equipment to assist with accessing the general education curriculum.

The need for students with special needs to have speech therapy, physical therapy or other related services presents a significant challenge to the school district and the special education teacher. In Montana, there is not only an acute need for special education teachers but also for these related service providers. Although remote supervision provides one solution, it may be delivered at times when the teacher is not available. The teachers that were using remote related services provision said it was more common that a paraeducator or teaching assistant was with the 
student while the remote related services were delivered. This can also present challenges to the teacher in that the related services provider is not on site and needs to communicate the specifics of the student's goals and progress remotely.

Jones and his colleagues [11] in their review of the literature noted that a significant predictor of teachers' career decisions is "their commitment to their schools and to the teaching profession" (p.365). From the interviews in this study, it is evident that for those teachers already working within a school or a district that their commitment to their schools extends to moving into a new specialty area. They have moved to the field of special education. These teachers have established their teaching skills and willingly take on the challenge of the special education position. One avenue for rural schools to explore is to recruit teachers they currently have already in their school. Childe [5] described the recruitment of teachers in rural Georgia as specifically targeting individuals who had their roots in the local community to guard against attrition from the project.

One incentive to add to recruitment is support from the state in meeting the cost of university tuition as teachers take coursework towards their endorsement. In rural areas, there is a need for training and education in an online format. With travelling distances in rural states, it is unrealistic to expect these teachers to commit to traveling great distances for their further education. In Montana, the universities providing special education coursework have met this need with online delivery.

As these teachers learned their new role in special education, they developed an appreciation for the isolation of the role of that teacher in the rural school. Some teachers had previously taught in a general education classroom, so experienced that more keenly. They found the transition from going from being a member of a team to being that one teacher in the school with the special education expertise was somewhat isolating. It provided a new perspective for them. Those teachers that had had the opportunity to teach in general education were able to appreciate the challenges of the special education teacher in working with colleagues who thought that the students with IEPs were not their responsibility. However many of the teachers also commented that despite this they found it very rewarding to teach in special education and were committed to continuing to teach in that field. Mentoring programs are one way in which teachers can be connected to another specialist. However, the challenge is to maintain that connection over a distance.

\section{Limitations}

In this study, participants were chosen because they were part of the OPI Special Education Endorsement Project. Therefore, they are not representative of all teachers in Montana that are teaching in special education while also completing a special education endorsement. Although they were assured that their participation in the study would not affect their participation in the OPI Special Education Endorsement Project, they may have been more likely to participate because they felt an obligation to the project as the state was providing them with tuition support to take university coursework.

This study did not differentiate between teachers that had previous experience teaching in the general education classroom with those who had not. It also did not differentiate between teachers that had previously taught at the school and those teachers that were new to the school. The sample is small and the conclusions drawn cannot be generalized to a larger group of teachers in the state or in the nation.

\section{Conclusion}

Projects such as the OPI Special Education Endorsement Project enable schools in rural areas of Montana to fill positions and support teachers. In programs such as these, there is the possibility that teachers can be recruited back into general education. To ensure some stability in the school the OPI Special Education Endorsement Project in Montana requires a commitment from those teachers to teach for a minimum of two years beyond completing their three years in special education. This guarantees that that school will have that special educator in place for at least five years, that is three years as they are being trained, and for two subsequent years. Ideally, these schools would want a much longer commitment from these teachers. It warrants further investigation to see if schools that have teachers that move from a general education positon to a special education position are more successful at keeping the teacher in that position. This study also did not differentiate between the length of a teacher's previous tenure in a general education classroom and the benefits and challenges that were found. Further study could be conducted on whether the length of previous teaching experience was a factor in facilitating teachers adjusting to the special education position.

The challenge for states to recruit teachers to fill special education positons is not likely to change in the near future. If smaller schools are to be successful in their recruitment efforts it will take supports from the state to provide mentoring for teachers, education programs which enable teachers to take coursework online and ideally some financial incentive for teachers.

\section{References}

[1] Berry, A. B., Petrin, R. A., Gravelle, M. L., and Farmer, T. W., (2012), 'Issues in Special Education Teacher Recruitment, Retention, and Professional Development: Considerations in Supporting Rural 
Teachers', Rural Special Education Quarterly, 30(4), pp. 3-11.

[2] Dewey, J., Sindelar, P. T. Bettini, E., Boe, E. E., Rosenberg, M. S., and Leko, C., (2017), 'Explaining the Decline in Special Education Teacher Employment from 2005-2012', Exceptional Children, 83(3), pp. 315-329.

[3] Viadero, D., (January 23, 2018), 'Teacher Recruitment and Retention: It's Complicated', Education Week.

[4] Casey, P., Dunlap K., Brister, H., and Davidson, M., (2011), 'I Only Wish I'd Known: Voices of Novice

Alternatively Certified Special Education Teachers', International Journal of Special Education, 26(1), pp. 182-190.

[5] Childre, A. L., (2014), 'Preparing Special Educators Highly Qualified in Content: Alternative Route

Certification for Unlicensed Teachers in Rural Georgia', Rural Special Education Quarterly, 33(1), pp. 23-30.

[6] Erickson, A. S. G., Noonan, P. M., and McCall, Z. (2012), 'Effectiveness of Online Professional Development for Rural Special Educators', Rural Special Education Quarterly, 31(1), pp. 22-32.

[7] United States Census Bureau, www.census.gov. (Access date: 2 February 2017).

[8] Burdge, J. A., Fishbaugh, M. S. E. and Christensen, L., (2003), 'OPI Special Education Endorsement Project: A State-University Partnership', Rural Educator, 24(3), pp. 20-26.

[9] Cross, F., (2016), Teacher Shortage Areas Nationwide Listing 1990-1991 2016-2017. U. S. Department of Education Office of Postsecondary Education.

[10] Quinlan, M. and Furios, S., (2016), 'Critical Teacher Shortages: Identification of Schools and Licensure and Endorsement Areas Impacted by Critical Quality Educator Shortages for the 2016-17 School Year', Montana Office of Public Education Report to the Board of Public Education.

[11] Jones, N. D., Youngs, P., and Frank, K. A., (2013), 'The Role of School-Based Colleagues in Shaping the Commitment of Novice Special and General Education Teachers', Exceptional Children, 79(3), pp.365-383.
[12] Vannest, K. J. and Hagan-Burke, S. (2010), 'Teacher Time Use in Special Education', Remedial and Special Education, 31, pp.126-142. 